\title{
Comparison of etomidate and propofol on intubating conditions and the onset time associated with cisatracurium administration
}

\author{
Young-Kwon Ko, Yoon-Hee Kim, Sang-Il Park, Woo Suk Chung, Chan Noh, \\ and Jung-Un Lee \\ Department of Anesthesiology and Pain Medicine, Chungnam National University College of Medicine, Daejeon \\ Korea
}

\begin{abstract}
Background: This study compared intubating conditions and the onset time associated with administration of cisatracurium, a nondepolarizing neuromuscular blocker with a relatively slow onset, according to prior injection of one of two intravenous anesthetic agents: propofol or etomidate.

Methods: Forty-six female patients, undergoing general anesthesia and endotracheal intubation for elective surgery, were randomized to two groups; group P were administered propofol $(2 \mathrm{mg} / \mathrm{kg})$ prior to cisatracurium $(0.2 \mathrm{mg} / \mathrm{kg})$; group E were administered etomidate $(0.3 \mathrm{mg} / \mathrm{kg})$ prior to cisatracurium $(0.2 \mathrm{mg} / \mathrm{kg})$. We measured intubating conditions and the onset time according to the types of intravenous anesthetic administered. Measurements of heart rate (HR), systolic blood pressure (SBP) and diastolic blood pressure (DBP) were taken immediately prior to induction; immediately and 1 min after IV anesthetic administration; and immediately and 1, 2, 3, 4, 5, 7, and 15 min after endotracheal intubation. Results: Intubating conditions were superior in group $\mathrm{E}$ compared with group $\mathrm{P}(\mathrm{P}=0.009)$. The average onset time of cisatracurium was more rapid in group $\mathrm{E}(155.74 \pm 32.92 \mathrm{~s}$ vs. $185.26 \pm 38.57 \mathrm{~s}$ in group $\mathrm{P} ; \mathrm{P}=0.008)$. There were no group differences in SBP, DBP, and HR following intravenous anesthetic drug injection and endotracheal intubation. However, SBP and DBP were substantially higher in group $\mathrm{E}$ after endotracheal intubation.

Conclusions: Etomidate improves intubating conditions and provide a more rapid onset time of cisatracurium during anesthetic induction compared to propofol.
\end{abstract}

Key Words: Cisatracurium, Etomidate, Intratracheal intubation, Neuromuscular blockade, Propofol.

Corresponding author: Yoon-Hee Kim, M.D., Ph.D.

Department of Anesthesiology and Pain Medicine, Chungnam National University College of Medicine, 282, Munhwa-ro, Jung-gu, Daejeon 301-721, Korea

Tel: 82-42-280-7841, Fax: 82-42-280-7968

E-mail: yhkim0404@cnu.ac.kr

Received: September 15, 2014.

Revised: 1st, October 2, 2014; 2nd, November 11, 2014.

Accepted: November 27, 2014.

Korean J Anesthesiol 2015 April 68(2): 136-140

http://dx.doi.org/10.4097/kjae.2015.68.2.136

\section{Introduction}

Cisatracurium, an isomer of atracurium, is a potent nondepolarizing neuromuscular blocking agent (NMBA) of intermediate duration. Cisatracurium is metabolized by Hoffmann elimination, and thus confers benefits through being independent of hepatic and renal function [1]. In contrast to atracurium, cisatracurium does not release histamine in clinical doses, and therefore possesses stable hemodynamic properties [2]. However, despite these advantages, its use is limited due to its rela-

(c) This is an open-access article distributed under the terms of the Creative Commons Attribution Non-Commercial License (http://creativecommons.org/ licenses/by-nc/3.0/), which permits unrestricted non-commercial use, distribution, and reproduction in any medium, provided the original work is properly cited. 
tively slow onset, and association with unsatisfactory intubating conditions, compared with other nondepolarizing NMBAs $[3,4]$.

The onset time of neuromuscular blockade depends on both circulatory and non-circulatory factors. Circulatory factors determine the distribution of neuromuscular blocking agents from the site of injection to the different muscles. Accordingly, muscular perfusion and resultant onset of neuromuscular block may be affected by the intravenous anesthetics during anesthetic induction [5]. In a study of the hemodynamic effects of an induction dose of propofol of $2.5 \mathrm{mg} / \mathrm{kg}$, and etomidate at $0.3 \mathrm{mg} /$ $\mathrm{kg}$, propofol was associated with significant decreases in systolic (19.9\%) and diastolic (25.3\%) arterial pressure, a 17.3\% decrease in cardiac output and an $11.6 \%$ reduction in systemic vascular resistance. In contrast, minimal changes in hemodynamics were observed using etomidate [6]. Therefore, we anticipate superior intubating conditions, and more rapid onset of neuromuscular blockade using etomidate, through maintenance of cardiac output during anesthetic induction, and as a consequence of neuromuscular blockers reaching the neuromuscular junction more rapidly compared with propofol.

To directly address this, we compared intubating conditions, onset time to adequate neuromuscular blockade, and hemodynamic changes following administration of cisatracurium at 0.2 $\mathrm{mg} / \mathrm{kg}$ with either propofol $(2 \mathrm{mg} / \mathrm{kg})$ or etomidate $(0.3 \mathrm{mg} / \mathrm{kg})$.

\section{Materials and Methods}

Approval for the study was granted by the hospital's Institutional Review Board. Written consent was obtained from all patients. Forty-six female patients aged between 20 and 65 years, classified by the American Society of Anesthesiologists as I or II, and scheduled to undergo general anesthesia and endotracheal intubation for elective surgery, were enrolled in the study. Exclusion criteria included any disorders of the cardiovascular, hepatic, renal, or neuromuscular systems, according either to medical history or clinical examination. Patients for whom problematic intubation and mask ventilation was expected, and patients on medications known to interact with neuromuscular blocking drugs; e.g., antibiotics, calcium channel blockers, and magnesium sulfate, were also excluded. A body mass index of $<19$ or $>28$ represented a further exclusion criterion; finally, pregnant or breastfeeding females were also excluded.

All patients were premedicated with $0.05 \mathrm{mg} / \mathrm{kg}$ midazolam, injected intramuscularly $30 \mathrm{~min}$ prior to anesthetic induction. Standardized monitoring, using a peripheral pulse oximeter, noninvasive measurement of blood pressure, electrocardiogram and end-tidal partial pressure of carbon dioxide, was continuously applied during anesthesia.

All patients were preoxygenated with $100 \%$ oxygen, and administered remifentanil at $1 \mu \mathrm{g} / \mathrm{kg}$ for $30 \mathrm{~s}$ prior to intravenous injection of either propofol ( $2 \mathrm{mg} / \mathrm{kg}$; group P) or etomidate $(0.3 \mathrm{mg} / \mathrm{kg}$; group E) for $20 \mathrm{~s}$. Following loss of eyelash reflex and decrease of bispectral index score (BIS, Aspect A-2000 BIS ${ }^{\circledR}$ monitor, Aspect Medical Systems, Natick, MA, USA) to below 60 , cisatracurium was injected at $0.2 \mathrm{mg} / \mathrm{kg}$. Contraction of the adductor pollicis muscle was measured using a TOF-Watch $\mathrm{SX}^{\circledR}$ monitor (TOF-Watch $\mathrm{SX}^{\circledR}$; Organon Ltd., Dublin, Ireland). The ulnar nerve was stimulated supramaximally at the forearm, using repetitive train-of-four (TOF) stimuli $(2 \mathrm{~Hz}$ for $2 \mathrm{~s}$ ) at $15 \mathrm{~s}$ intervals. To evaluate the degree of neuromuscular blockade, superficial electrodes were placed on the ulnar nerve of the forearm, and all fingers except the thumb were fixated to evaluate contracture of the adductor pollicis of the thumb following induction of anesthesia. The onset time was defined as the time from the end of the injection of cisatracurium to the time of maximum twitch depression. Onset time of cisatracurium was evaluated by a physician blinded to the group assignment. The temperature of the palm, the site at which neuromuscular function was monitored, was maintained at $>33^{\circ} \mathrm{C}$.

Intubating conditions were graded while performing oral endotracheal intubation $90 \mathrm{~s}$ after injection of cisatracurium by a skilled anesthesiologist blinded to the group assignment: failure of intubation was considered when it could not be performed within $15 \mathrm{~s}$. Intubating conditions were graded using the scoring scale initially described by Cooper et al. [7] (Table 1). Conditions were classified as excellent $(0-1)$, good (2-3), poor (4-5), or impossible (6-9). Measurements of heart rate (HR), systolic blood pressure (SBP) and diastolic blood pressure (DBP) were taken immediately prior to induction; immediately and $1 \mathrm{~min}$ after IV anesthetic administration; and immediately and 1, 2, 3, 4, 5,7 , and $15 \mathrm{~min}$ after tracheal intubation. Following intubation, all patients were maintained with sevoflurane (1.5\%) and 50\%

Table 1. Assessment of Intubating Conditions

\begin{tabular}{lccc}
\hline & & & \\
\hline Criteria & 0 & 1 & Score \\
Jaw relaxation & Complete & Moderate & Minimal \\
Vocal cord Status & Open & Slight moving & Closing \\
Diaphragmatic response & None & Slight Moving & Closed \\
\hline
\end{tabular}

Adapted from Cooper et al. [7] Intubating conditions were rated more highly if one of the three conditions required was not met. 
oxygen without any stimulus. Patients were monitored for side effects.

The sample size was calculated such that 23 patients per group were required for a 0.05 level of significance and $80 \%$ power to detect improvements with an at least $50 \%$ group difference with respect to excellent intubating condition.

Patients were randomly allocated to two groups, each comprising 23 patients. Random allocation was performed with a randomization code, such that allocation was $1: 1$ to each group, using a block randomization method following screening. Randomization procedures were applied by an individual independent of the study.

Data were processed using the R statistical software ( $\mathrm{R} \mathrm{De}$ velopment Core Team, Vienna, Austria). Quantitative data were expressed as mean $\pm \mathrm{SD}$. An independent t-test was used to assess group differences in demographic data (age, height, weight, BIS score). Intubating conditions were compared using Fisher's exact test: HR, SBP, DBP and the onset time of cisatracurium were evaluated using an independent t-test. A value of $\mathrm{P}<0.05$ was considered to indicate statistical significance.

Table 2. Demographic Data

\begin{tabular}{lcc}
\hline & Group P $(\mathrm{n}=23)$ & Group E $(\mathrm{n}=23)$ \\
\hline Age $(\mathrm{yr})$ & $42.30 \pm 10.91$ & $44 \pm 0.57$ \\
Height $(\mathrm{cm})$ & $157.04 \pm 5.55$ & $158.04 \pm 6.98$ \\
Weight $(\mathrm{kg})$ & $59.43 \pm 9.56$ & $57.70 \pm 6.79$ \\
BIS & $39.10 \pm 14.13$ & $41.52 \pm 15.32$ \\
\hline
\end{tabular}

Values are mean \pm SD. There were no significant group differences $(P$ $>0.05)$. BIS: bispectral index just before intubation, Group P: received propofol ( $2 \mathrm{mg} / \mathrm{kg})$, Group E: received etomidate $(0.3 \mathrm{mg} / \mathrm{kg})$.

Table 3. Intubating Conditions following Cisatracurium Administration

\begin{tabular}{ccc}
\hline Intubating conditions & Group P $(\mathrm{n}=23)$ & Group E $(\mathrm{n}=23)$ \\
\hline Excellent & 16 & $23^{*}$ \\
Good & 5 & $0^{*}$ \\
Poor & 2 & $0^{*}$
\end{tabular}

Values are number of patient. Group P: received propofol $(2 \mathrm{mg} / \mathrm{kg})$, Group E: received etomidate $(0.3 \mathrm{mg} / \mathrm{kg})$. *Significant group difference $(\mathrm{P}<0.05)$.

Table 4. Onset Time following Cisatracurium Administration

\begin{tabular}{ccc}
\hline & Group P $(\mathrm{n}=23)$ & Group E $(\mathrm{n}=23)$ \\
\hline Onset time & $185.26 \pm 38.57$ & $155.74 \pm 32.92 *$ \\
\hline
\end{tabular}

Values are mean \pm SD. Onset time; the time between cisatracurium injection and the TOF count reaching zero. Group P: received propofol (2 $\mathrm{mg} / \mathrm{kg})$, Group E: received etomidate $(0.3 \mathrm{mg} / \mathrm{kg})$. *Significant group difference $(\mathrm{P}<0.05)$.

\section{Results}

A total of 46 patients received the study treatment. No patients were withdrawn due to non-compliance, missing data, or adverse effects occurring during the study. There were no significant group differences in age, gender, height, or weight (Table 2).

Endotracheal intubation was successful on the first attempt in all patients. Intubating conditions scores were significantly lower in group $\mathrm{E}$ compared with group $\mathrm{P}(\mathrm{P}=0.009)$. Intubating conditions were excellent in all of the patients in group $\mathrm{E}$, and were excellent, good, and poor in 16, 5, and 2 patients in group $\mathrm{P}$ (Table 3). The onset time of cisatracurium was significantly different between groups $(\mathrm{P}=0.008)$, and was more rapid in group E (155.74 $\pm 32.92 \mathrm{~s}$ ) compared with group P (185.26 \pm 38.57 s; Table 4).

There were no group differences in SBP, DBP, and HR following intravenous anesthetic drug injection and endotracheal intubation (Figs. 1, 2 and 3). However, SBP and DBP were substantially higher in group E following endotracheal intubation. The BIS screens during anesthetic induction did not differ between the groups.

\section{Discussion}

The present study compared the effects of the intravenous anesthetics etomidate and propofol on the onset time of cisatracurium, subsequent changes in intubating conditions and hemodynamic changes. Etomidate provided better intubating con-

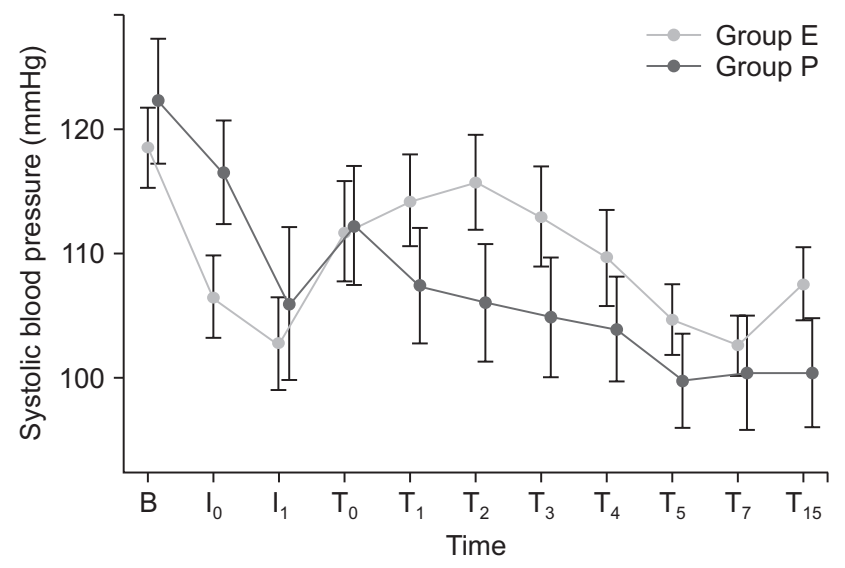

Fig. 1. Changes in systolic arterial pressure in each group during induction. Values are mean $\pm \mathrm{SD}$. There were no significant group differences $(\mathrm{P}>0.05)$. Group $\mathrm{P}$ : received propofol $(2 \mathrm{mg} / \mathrm{kg})$, Group E: received etomidate $(0.3 \mathrm{mg} / \mathrm{kg})$. B: baseline, $\mathrm{I}_{0}$ : immediately after IV anesthetics, $\mathrm{I}_{1}: 1 \mathrm{~min}$ after $\mathrm{IV}$ anesthetics, $\mathrm{T}_{0}$ : immediately after endotracheal intubation, $\mathrm{T}_{1}: 1 \mathrm{~min}$ after endotracheal intubation, $\mathrm{T}_{2}: 2 \mathrm{~min}$ after endotracheal intubation, $\mathrm{T}_{3}: 3 \mathrm{~min}$ after endotracheal intubation, $\mathrm{T}_{4}: 4 \mathrm{~min}$ after endotracheal intubation, $\mathrm{T}_{5}: 5 \mathrm{~min}$ after endotracheal intubation, $\mathrm{T}_{7}: 7 \mathrm{~min}$ after endotracheal intubation, $\mathrm{T}_{15}: 15$ min after endotracheal intubation. 


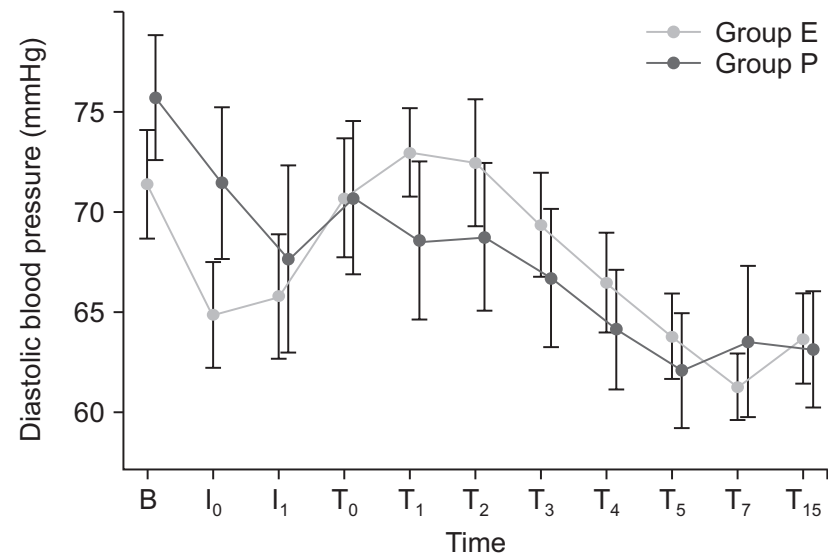

Fig. 2. Changes in diastolic arterial pressure in each group during induction. Values are mean \pm SD. There were no significant group differences $(\mathrm{P}>0.05)$. Group $\mathrm{P}$ : received propofol $(2 \mathrm{mg} / \mathrm{kg})$; group E: received etomidate $(0.3 \mathrm{mg} / \mathrm{kg})$. B: baseline, $\mathrm{I}_{0}$ : immediately after IV anesthetics, $I_{1}: 1 \mathrm{~min}$ after IV anesthetics, $T_{0}$ : immediately after endotracheal intubation, $\mathrm{T}_{1}: 1 \mathrm{~min}$ after endotracheal intubation, $\mathrm{T}_{2}: 2$ min after endotracheal intubation, $\mathrm{T}_{3}: 3 \mathrm{~min}$ after endotracheal intubation, $\mathrm{T}_{4}: 4 \mathrm{~min}$ after endotracheal intubation, $\mathrm{T}_{5}: 5 \mathrm{~min}$ after endotracheal intubation, $\mathrm{T}_{7}: 7 \mathrm{~min}$ after endotracheal intubation, $\mathrm{T}_{15}: 15$ min after endotracheal intubation.

ditions and rapid neuromuscular blockade after cisatracurium administration during anesthetic induction compared to propofol. As many other studies have implied, this could be due to the relatively maintained cardiac output following administration of etomidate which allows more rapid onset of cisatracurium at the neuromuscular junction. In our present study, however, hemodynamic parameters were statistically insignificant between the two groups although there was a high tendency. Because the present sample size was determined based on comparing the intubating conditions, this may be too small sample size when comparing the heart rate and blood pressure between the two groups.

The onset time of neuromuscular blockers is influenced by factors such as potency, dosage, and cardiovascular status. Numerous factors determine the distribution of NMBA, from the injection site to the neuromuscular junction; latency to muscle relaxation may also differ according to changes in cardiac output. A previous study suggested that a small dose $(70-100 \mu / \mathrm{kg})$ of ephedrine, administered during anesthetic induction to increase cardiac output without causing major side effects, facilitates neuromuscular relaxation [8], intubating conditions might also be improved. Another report stated that when a priming dose of cisatracurium together with a low dose of ephedrine were injected simultaneously prior to an intubating dose, onset time and intubating conditions were improved [9].

Selecting intravenous anesthetics that maintain or increase cardiac output, such as ketamine or etomidate, will facilitate neuromuscular relaxation. One study showed that low doses of

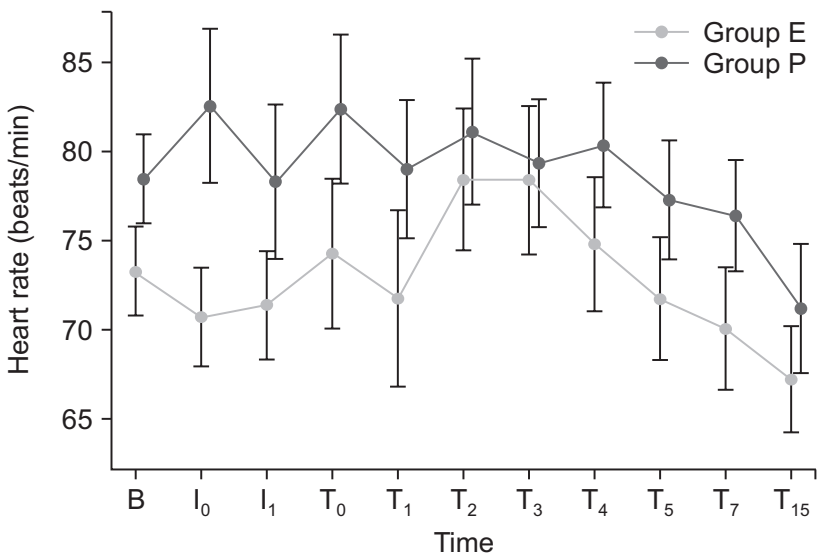

Fig. 3. Changes in heart rate in each group during induction. Values are means $\pm \mathrm{SD}$. There were no significant group differences $(\mathrm{P}>0.05)$. Group P: received propofol $(2 \mathrm{mg} / \mathrm{kg})$; group E: received etomidate $(0.3$ $\mathrm{mg} / \mathrm{kg}$ ). B: baseline, $\mathrm{I}_{0}$ : immediately after IV anesthetics, $\mathrm{I}_{1}: 1$ min after IV anesthetics, $\mathrm{T}_{0}$ : immediately after endotracheal intubation, $\mathrm{T}_{1}: 1 \mathrm{~min}$ after endotracheal intubation, $\mathrm{T}_{2}: 2 \mathrm{~min}$ after endotracheal intubation, $\mathrm{T}_{3}: 3 \mathrm{~min}$ after endotracheal intubation, $\mathrm{T}_{4}: 4 \mathrm{~min}$ after endotracheal intubation, $\mathrm{T}_{5}: 5 \mathrm{~min}$ after endotracheal intubation, $\mathrm{T}_{7}: 7 \mathrm{~min}$ after endotracheal intubation, $\mathrm{T}_{15}: 15 \mathrm{~min}$ after endotracheal intubation.

ketamine $(0.5 \mathrm{mg} / \mathrm{kg})$ following propofol - rocuronium induction shortened the onset time neuromuscular blockade [10]. Gill and Scott [11] reported that following anesthetic induction with etomidate, propofol, and thiopental, etomidate significantly improved the onset time of vecuronium compared with the other two agents. A significant negative correlation between onset time of neuromuscular blockade and change in mean arterial pressure was also observed.

Propofol injection precipitates vascular dilatation, decreased preload and afterload, and impaired heart contractility, resulting in hypotension. Because the heart is not synchronized with heart compensatory mechanisms, such as increases in heart rate, cardiac output is decreased [12]. These changes were most pronounced $1 \mathrm{~min}$ after injection of propofol. At 5 and $10 \mathrm{~min}$, heart rate was decreased significantly.

Certain factors influence the effects of intravenous anesthetics on intubating conditions, regardless of the onset time of neuromuscular relaxation. First, injected anesthetics may differ in terms of anesthetic depth. Relatively high doses increase anesthetic depth, improving intubating conditions and thereby creating an experimental fallacy. Because propofol, at $2 \mathrm{mg} / \mathrm{kg}$, and etomidate, at $0.3 \mathrm{mg} / \mathrm{kg}$, were titrated at the same clinical endpoint in the present experiment, we suspect that anesthetic depth at the time of intubation may have differed. However, the analgesic effects of remifentanil injected during induction increased the anesthetic depth, and may countervail differences in IV anesthetic depth. Also there was no difference in anesthetic depth between the two groups, as indexed by BIS. Second, intra- 
venous anesthetics may alter intubating conditions by restricting laryngeal and pharyngeal reactivity. When given intravenous anesthetics without neuromuscular blockers, visualization of the vocal cords by standard laryngoscopy was possible more often after propofol rather than other agents $[13,14]$. However, this may be relevant in situations in which the endotracheal intubation was attempted without the use of neuromuscular blocker. Lieutaud et al. [15] reported that in patients receiving the same dose of anesthetics, with or without atracurium, intubating conditions depended much more on neuromuscular blockade than on depression of the central nervous system induced by anesthetics. Therefore, in the present study, the superior intubating conditions of group E compared with group P can be explained in terms of the more rapid onset time of cisatracurium.

Our study design has some limitations. First, most of the drugs for anesthesia (midazolam, remifentanil, and sevoflurane) may have influenced the patient's hemodynamics and the onset time of neuromuscular blocking agents, thus possibly having a certain effect on our results. Second, we did not measure the TOF ratio at $90 \mathrm{~s}$ after cisatracurium administration. However etomidate showed a more rapid onset time at adductor pollicis compared to propofol. Although onset time at the larynx was different than that at the adductor pollicis [16], we suspect that etomidate may also reduce the onset time at the larynx after cisatracurium, which may improve intubating conditions.

In conclusion, when using cisatracurium, etomidate provides better intubating conditions and a more rapid onset of neuromuscular blockade during anesthetic induction compared to propofol.

\section{Acknowledgments}

This work was supported by the research grant of Chungnam National University.

\section{References}

1. Welch RM, Brown A, Ravitch J, Dahl R. The in vitro degradation of cisatracurium, the R, cis-R'-isomer of atracurium, in human and rat plasma. Clin Pharmacol Ther 1995; 58: 132-42.

2. Doenicke A, Soukup J, Hoernecke R, Moss J. The lack of histamine release with cisatracurium: a double-blind comparison with vecuronium. Anesth Analg 1997; 84: 623-8.

3. Kirov K, Motamed C, Decailliot F, Behforouz N, Duvaldestin P. Comparison of the neuromuscular blocking effect of cisatracurium and atracurium on the larynx and the adductor pollicis. Acta Anaesthesiol Scand 2004; 48: 577-81.

4. Lee H, Jeong S, Choi C, Jeong H, Lee S, Jeong S. Anesthesiologist's satisfaction using between cisatracurium and rocuronium for the intubation in the anesthesia induced by remifentanil and propofol. Korean J Anesthesiol 2013; 64: 34-9.

5. Fuchs-Buder T, Sparr HJ, Ziegenfuss T. Thiopental or etomidate for rapid sequence induction with rocuronium. Br J Anaesth 1998; 80: 504-6.

6. Brüssel T, Theissen JL, Vigfusson G, Lunkenheimer PP, Van Aken H, Lawin P. Hemodynamic and cardiodynamic effects of propofol and etomidate: negative inotropic properties of propofol. Anesth Analg 1989; 69: 35-40.

7. Cooper R, Mirakhur RK, Clarke RS, Boules Z. Comparison of intubating conditions after administration of Org 9246 (rocuronium) and suxamethonium. Br J Anaesth 1992; 69: 269-73.

8. Kim KS, Cheong MA, Jeon JW, Lee JH, Shim JC. The dose effect of ephedrine on the onset time of vecuronium. Anesth Analg 2003; 96: $1042-6$.

9. Leykin Y, Dalsasso M, Setti T, Pellis T. The effects of low-dose ephedrine on intubating conditions following low-dose priming with cisatracurium. J Clin Anesth 2010; 22: 425-31.

10. Topcuoglu PT, Uzun S, Canbay O, Pamuk G, Ozgen S. Ketamine, but not priming, improves intubating conditions during a propofolrocuronium induction. Can J Anaesth 2010; 57: 113-9.

11. Gill RS, Scott RP. Etomidate shortens the onset time of neuromuscular block. Br J Anaesth 1992; 69: 444-6.

12. Schmidt C, Roosens C, Struys M, Deryck YL, Van Nooten G, Colardyn F, et al. Contractility in humans after coronary artery surgery. Anesthesiology 1999; 91: 58-70.

13. McKeating K, Bali IM, Dundee JW. The effects of thiopentone and propofol on upper airway integrity. Anaesthesia 1988; $43: 638-40$.

14. Erhan E, Ugur G, Gunusen I, Alper I, Ozyar B. Propofol - not thiopental or etomidate - with remifentanil provides adequate intubating conditions in the absence of neuromuscular blockade. Can J Anaesth 2003; 50: 108-15.

15. Lieutaud T, Billard V, Khalaf H, Debaene B. Muscle relaxation and increasing doses of propofol improve intubating conditions. Can J Anaesth 2003; 50: 121-6.

16. Kim KS, Chung CW, Shin WJ. Cisatracurium neuromuscular block at the adductor pollicis and the laryngeal adductor muscles in humans. Br J Anaesth 1999; 83: 483-4. 